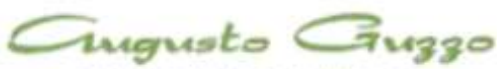

REVISTA ACADEMICA

\title{
Incidência Do Vírus HIV Em Um Município Da Grande São Paulo No Ano De 2014
}

\author{
Incidence Of The HIV Virus In A Municipality Of São Paulo In 2014
}

\author{
Amanda Ruas Almeida1, Marco Aurélio Ferreira Federige² \\ 1.Especialista em microbiologia e graduada em Enfermagem, atua na prefeitura de Itapevi como socorrista. E-mail \\ <profelianajpra@hotmail.com> \\ 2. Mestre bioquímica, Farmacêutico, Bioquímico Prof. de microbiologia da Faculdade FMU. Especialista em ciências da saúde.
}

\section{Resumo}

O presente estudo tem como objetivo verificar a incidência do vírus HIV, de importância pública, analisar possíveis meios de prevenção e cuidados com a população vulnerável. A metodologia utilizada foi a pesquisa descritiva, epidemiológica, transversal, por meio da análise das fichas de notificação do Sistema de Informação de Agravos de Notificação. Os resultados obtidos demonstraram maior incidência em população masculina, heterossexual, jovem, parda e com baixa escolaridade. Concluiu-se que as políticas públicas devam ser voltadas para a prevenção, principalmente, daquela população, cujo fornecimento de testes rápidos para diagnóstico, educação em saúde e a distribuição gratuita de preservativos colaboram nos níveis de prevenção primária e secundária. Deve-se dar especial atenção às coinfecções e à informação distribuída à população.

Palavras-chave: HIV, Incidência, Prevenção, Vulnerabilidade

\begin{abstract}
This study aims to determine the incidence of the HIV virus, of public importance, analyze possible means of prevention and care of the vulnerable population. The methodology used was descriptive, epidemiological, cross through the analysis of reporting forms the Notifiable Diseases Information System. The results were an increased incidence in young, brown, low education, heterosexual and male population. It was concluding that public policies should be geared primarily to prevent this population, providing rapid tests for diagnosis, health education and free condoms collaborate in the levels of primary and secondary prevention. And that one should pay special attention to co-infections and health education.
\end{abstract}

Keywords: HIV, Incidence, Prevention, Vulnerability

272 ALMEIDA, M.R.; FEDERIGE, M.A.F.: Incidência Do Vírus Hiv Em Um Município Da Grande São Paulo No Ano De 2014. 


\section{Introdução}

O vírus da imunodeficiência humana (HIV) é um vírus que apresenta duas cópias de RNA (ácido ribonucleico) de cadeia simples encapsuladas por um núcleo-capsídeo, capsídeo e envelope externo composto por uma bicamada fosfolipídica em formato esférico. Sua replicação se dá através da integração de seu DNA (gerado pela enzima transcriptase reversa) ao DNA do hospedeiro. (Werson et al. 2013).

Os primeiros relatos acerca de imunodeficiência observados datam do ano de 1975, porém o primeiro caso descrito sobre a depressão imunológica aguda foi no ano de 1981, e somente em 1982 o vírus da imunodeficiência humana foi identificado (Paschoal et al. 2014). A principal forma de transmissão do HIV é por via sexual (Pereira et al. 2014). Sendo também o compartilhamento de seringas e agulhas, principalmente para administração de drogas injetáveis ilícitas, um meio que ainda acarreta grande número de contágios (Ferreira et al. 2012). Sabe-se também que na presença de outras doenças sexualmente transmissíveis (DSTs) o risco de transmissão do HIV é quatro a cinco vezes maior (Pereira et al. 2014).

Outro meio de contágio é através de transfusão sanguínea, visto que no Brasil a triagem de doadores de sangue por testes de biologia molecular não era rotineiramente empregada, isso abria a possibilidade de que o doador estivesse em janela imunológica, não sendo detectado o vírus e desta forma transmitindo-o (Neto et al. 2009). Porém a partir de junho de 2014 a Resolução da Diretoria Colegiada $n^{\circ} 34$, em seu artigo 89 , item $V$ prevê dois testes em paralelo para HIV 1 e 2 . O primeiro diz respeito a um teste para detecção de anticorpo anti-HIV ou para detecção combinada antígeno/ anticorpo e o segundo teste para detecção de ácido nucléico do vírus HIV por técnica de biologia molecular. Acredita-se que o emprego desta nova resolução impedirá a transmissão do HIV por transfusão sanguínea, devido a uma diminuição do tempo de diagnóstico, estudos futuros poderão apontar a eficácia da medida.

Em pesquisa realizada em Goiânia, segundo Coelho et al. (2011), verificou-se um conhecimento geral insatisfatório sobre DST e síndrome da imunodeficiência adquirida (SIDA) entre adolescentes, sendo que muitos desconheciam sua real forma de contágio e prevenção. A camisinha tanto feminina quanto masculina mostra-se como o meio de prevenção mais satisfatório contra o HIV, considerando-se também a abstinência sexual, visto que impede o contato de fluídos corporais que contém o vírus (Pinheiro et al. 2013).

Há a necessidade de políticas públicas que tornem possível a realização de diagnóstico 
precoce da infecção pelo HIV, uma vez que muitos pacientes somente procuram assistência em fase avançada, tendo risco de progressão para a SIDA de acordo os níveis de CD4 e carga viral (Tibúrcio 2010). Um dos adventos mais utilizados nos serviços públicos atualmente é a oferta de testes rápidos anti-HIV, que detectam a presença de anticorpos no sangue ou fluído oral (Werson et al. 2013), são ofertados para a população em geral, principalmente às gestantes, por meio de aconselhamento dos profissionais para os usuários. Nesses aconselhamentos devese orientar sobre os riscos e os meios de prevenção do HIV (Marques et al. 2015), o resultado é observado entre 10 e 20 minutos, em caso positivo um teste confirmatório deve ser realizado e o profissional já orienta e encaminha o paciente logo após o resultado, para o serviço especializado (Werson et al. 2013).

No que tange a terapia antirretroviral, o Brasil foi um dos primeiros países a implementar a distribuição universal de medicamentos (Paschoal et al. 2014). Com este advento a infecção pelo HIV passou a ser considerada uma condição crônica, como a hipertensão e o diabetes, e não mais uma "sentença de morte" (Reis et al. 2011). O tratamento com a terapia antirretroviral combinada é altamente eficaz, inibe a replicação do HIV, proporcionando redução do RNA viral e, assim, é observada a elevação dos linfócitos $\mathrm{CD} 4+$, que são as células-alvo do HIV. Desta forma a recuperação da imunidade nos indivíduos infectados garante maior sobrevida, já que diminuem os riscos de infecções oportunistas (Ferreira et al. 2012 e Tibúrcio 2010).

Considerando os parâmetros da Organização Mundial de Saúde (OMS) a epidemia no Brasil é do tipo concentrada, afetando principalmente a população de homens que fazem sexo com homens (HSH), profissionais do sexo e pessoas que usam drogas injetáveis. Apesar da interiorização dos casos de AIDS, estes são mais concentrados em municípios mais populosos (Martins et al. 2014). Observa-se o fenômeno denominado de feminização da infecção pelo HIV, onde a infecção se dá em grande parte em mulheres jovens, pobres, com baixa escolaridade, negras e pardas, infectadas por via heterossexual em relações estáveis com parceiro único (Marques et al. 2015 e Pereira et al. 2014). Há uma estimativa de 718 mil indivíduos com HIV no Brasil, porém somente $80 \%$ destes com diagnóstico, tendo ainda uma maior proporção na população de 20 a 40 anos de idade, possivelmente devido a maior atividade sexual desta faixa etária (Martins et al. 2014).

O objetivo do estudo foi verificar a incidência do vírus HIV, através das variáveis, sexo, idade, etnia, orientação sexual e grau de escolaridade dos indivíduos notificados como portadores do vírus HIV em um município da grande São Paulo no ano de 2014, analisar possíveis meios de prevenção e cuidados com a população vulnerável. 
A metodologia trata de um estudo descritivo, epidemiológico, transversal, realizado por meio da análise documental das fichas do Sistema de Informação de Agravos de Notificação (SINAN), com Classificação Internacional de Doenças (CID) B 24 (doença pelo vírus da imunodeficiência humana não especificada), do ano de 2014, dentro de um município da Grande São Paulo. Como critério de inclusão utilizou-se as notificações de HIV de 2014 que não estavam em duplicidade no sistema, ou seja, os casos de notificação que já haviam sido alimentados no sistema em anos anteriores foram descartados. As notificações foram coletadas no SINAN, dentro do Departamento Técnico de Vigilância Epidemiológica (DTVE). E aprovada no comitê de ética em pesquisa sob o número do parecer 1.230.337. A análise estatística foi realizada comparando-se as variáveis sexo, etnia, idade, orientação sexual e escolaridade, independentemente e apresentadas em números absolutos e porcentagem.

Os resultados e discussões apontam que dos 76 casos novos notificados no município, no ano de 2014, 46 eram do sexo masculino, 60,5\%, e 30 do sexo feminino, 39,5\%, conforme demonstrado no gráfico 1.

\section{Frequência Segundo Sexo}

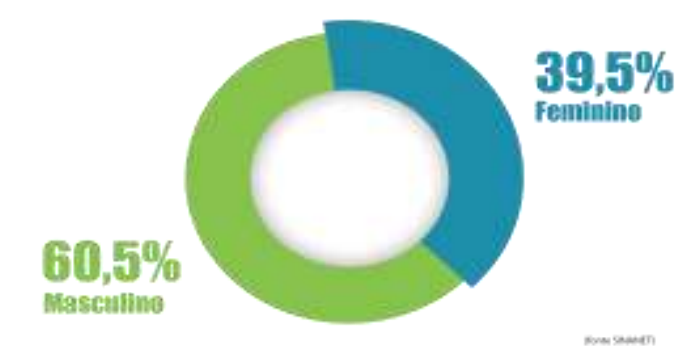

Fonte: notificados no município da Grande São Paulo do ano de 2014.

Observa-se um maior número de notificações em pessoas do sexo masculino o que nos leva a refletir sobre a causa desta diferença. Já é conhecida em literatura a vulnerabilidade masculina quanto ao risco de adquirir DST/HIV. Há que se notar também que historicamente os homens heterossexuais são vistos como imunes ao HIV, uma vez que grande parte dos casos se dá em homossexuais masculinos, isto contribui para a vulnerabilidade deste grupo (Junior et al. 2012).

É reconhecido que há um maior temor em contrair doenças sexualmente transmissíveis no sexo feminino do que no masculino, o que contribui para a prática de sexo seguro com as mulheres. Porém a ideia de fidelidade substitui o uso do preservativo podendo trazer riscos à prática sexual (Anjos et al. 2012). A frequência por orientação sexual, representada no gráfico 2 , seguiu a ordem: dentre 76 casos, 45 consideramse heterossexuais (59,5\%), 18 homossexuais $(23,5 \%)$ e cinco bissexuais (6,5\%), os demais (oito casos) 10,5\% preencheram a lacuna ignorado no momento da notificação. 


\section{Frequência por Orientação Sexual}

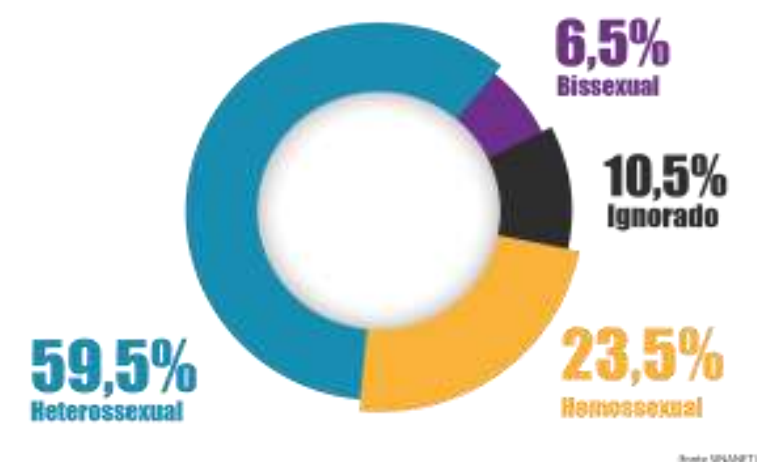

Fonte: notificados no município da Grande São Paulo do ano de 2014.

Apesar de ainda haver mundialmente um enfoque quanto a contaminação do vírus HIV na população $\mathrm{HSH}$, devido ao maior risco de transmissão do vírus por via anal, o estudo corroborou com a mudança do perfil epidemiológico brasileiro, onde se inicia um aumento da população heterossexual que convive com o vírus (Neto et al. 2010). Vale ressaltar outro fenômeno que vem sendo demonstrado em outros estudos, que é a denominada feminização da AIDS, visto que há um aumento de indivíduos heterossexuais contaminados, por consequência inicia-se o processo de feminização, onde já se observa um aumento da população feminina que convive com o vírus (Taquette e Meirelles 2012). Porém, no presente estudo, o número de mulheres contaminadas foi menor que o de homens.

Quanto a idade, representada no gráfico 3, dos casos notificados em 2014, as notificações iniciam-se na faixa etária entre 15 e 19 anos com 3 casos (4\%), com maior prevalência entre 20 e 34 anos, sendo 46 casos $(60,5 \%)$, tendo 23 casos (30\%) na faixa etária de 35 a 49 anos, decaindo e culminando na faixa entre 50 e 64 anos com 4 casos $(5,5 \%)$.

\section{Gráfico 3}

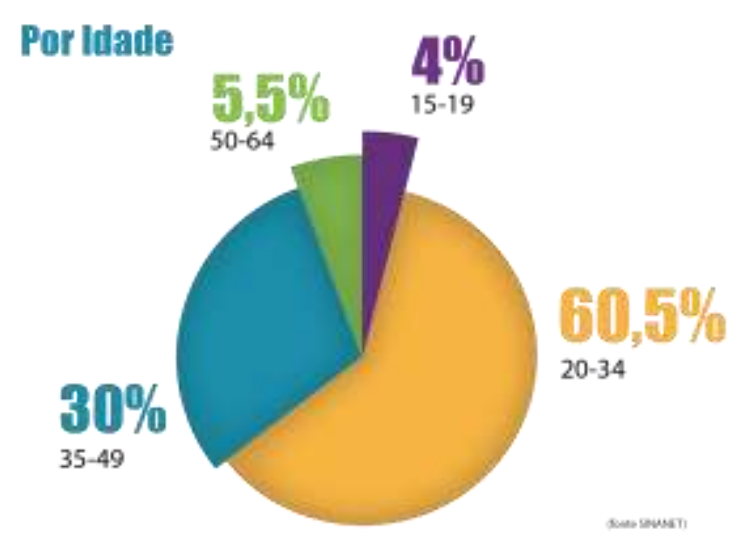

Fonte: notificados no município da Grande São Paulo do ano de 2014.

É evidenciado em diversos estudos, não só no Brasil, que há prevalência do vírus entre jovens. Isto se dá devido a diversos fatores característicos desta faixa etária tais como a intensa exposição à sexualidade, com constantes trocas de parceiros, o uso pouco frequente de preservativo, o consumo de álcool e outras substâncias psicoativas, bem como a imaturidade psicossocial, esta principalmente entre adolescentes, onde surge a ideia de onipotência e o desejo de correr riscos (Pereira et al. 2014).

Quanto a etnia dos indivíduos notificados, foi observado predominância da infecção em indivíduos pardos, sendo 41 casos 
(54\%), seguido por indivíduos da cor branca, sendo 26 casos $(34 \%)$ e por seis indivíduos da cor preta (8\%), três notificações foram preenchidas como ignorado (4\%), conforme observado no gráfico 4. Não houve notificações de indivíduos das cores amarela (orientais) ou vermelha (indígenas). Levando em consideração que no momento de preenchimento da notificação a cor do indivíduo deve ser auto referida.

\section{Gráfico 3}

\section{Frequência por Etnia}

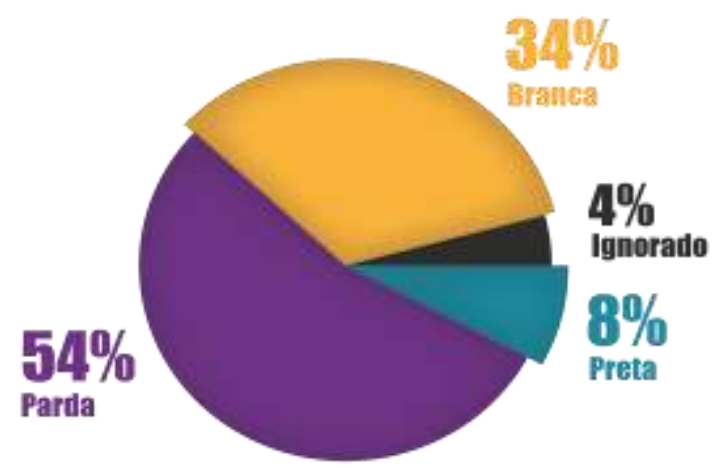

Fonte: notificados no município da Grande São Paulo do ano de 2014.

\section{A população denominada}

afrodescendente é considerada vulnerável devido a uma problematização histórica que tem por consequência a colocação desse grupo em situação socioeconômica desfavorável, o que dificulta seu acesso à informação e ao conhecimento (Silva et al. 2010). Porém devido a miscigenação característica do povo brasileiro, é natural que haja uma maior quantidade de indivíduos que não se consideram brancos nem pretos, tendo em seu meio termo a cor parda.
Em 2002 a variável raça/cor foi incorporada ao SINAN, isto possibilitou a percepção de uma modificação no perfil epidemiológico da doença tendo um crescimento entre a população que se considera afrodescendente e um declínio na população que se autodenomina branca (Araújo et al. 2010). O que foi evidenciado no presente estudo. Com relação a escolaridade, demonstrada no gráfico 5, um indivíduo $(1,5 \%)$ é analfabeto, dois indivíduos $(2,5 \%)$ possuem da primeira a quarta série do Ensino Fundamental incompleta, três indivíduos $(4 \%)$ possuem a quarta série do Ensino Fundamental completa, 12 indivíduos $(16 \%)$ possuem da quinta à oitava série do Ensino Fundamental incompleta, três indivíduos (4\%) possuem o Ensino Fundamental completo, 10 indivíduos (13\%) possuem Ensino Médio incompleto, 25 indivíduos (32,5\%) possuem o Ensino Médio completo, um indivíduo (1,5\%) possui Educação superior incompleta e três indivíduos (4\%) possuem Educação Superior completa. Vale ressaltar que este é um campo preenchido com defasagem pelos profissionais no momento da notificação, sendo que 16 fichas (21\%) foram preenchidas como ignorado.

Gráfico 3 


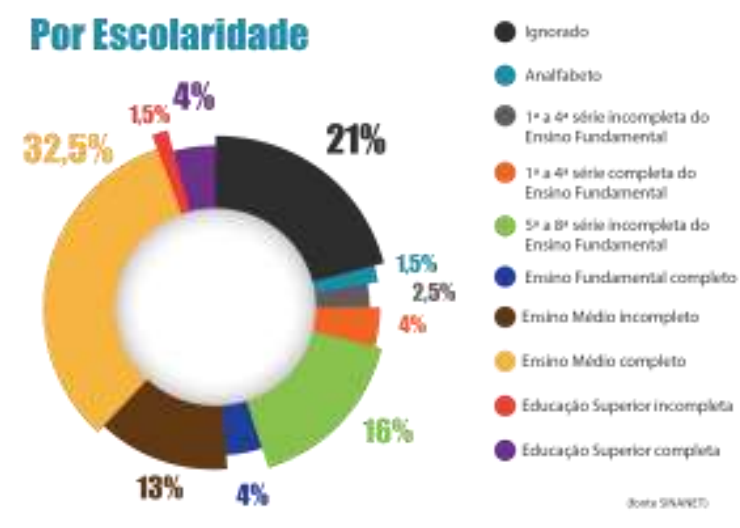

Fonte: notificados no município da Grande São Paulo do ano de 2014.

Observa-se um baixo nível de escolaridade dos indivíduos notificados. Apesar do grande número de notificações onde o nível de escolaridade foi ignorado, há uma notável quantidade de indivíduos com Ensino Médio completo e quatro indivíduos que iniciaram a Educação em Nível Superior, porém, ainda assim o número de indivíduos com Ensino Médio incompleto ou menos supera os demais. Isto demonstra o que outros estudos já apontaram como a inversão do início da epidemia, onde antes havia mais casos de pessoas com maior escolaridade e elevado nível socioeconômico, foi rapidamente mudado para pessoas com baixa renda e menor nível escolar, com consequente falta de acesso à informação sobre prevenção e os riscos na falta desta (Silva et al. 2011).

Muitos pacientes diagnosticados têm dificuldade para aderir ao tratamento seja pela não aceitação da infecção, ou por suposições de eventos adversos, um adequado apoio profissional e aconselhamento podem ajudar na aceitação da terapia destes pacientes e impedir que a infecção continue a ser transmitida. Há que se dar a devida atenção às coinfecções que representam grande risco de letalidade a estes pacientes. Doenças como tuberculose, sífilis e hepatites diminuem o tempo de vida, porém são absolutamente passíveis de tratamento.

\section{Considerações Finais}

Através do presente estudo foi possível concluir que a maioria dos indivíduos infectados era do sexo masculino, heterossexuais, jovens, pardos e de baixa escolaridade. Portanto é necessário que sejam criadas estratégias por meio do serviço público que atinjam essa população no quesito prevenção. Há que se manter a distribuição gratuita de preservativos masculinos e femininos em unidades de saúde, bem como em locais de grande fluxo de pessoas.

O fornecimento de testes rápidos para HIV e outras DSTs também entra como aliado na prevenção secundária da SIDA visto que o diagnóstico precoce possibilita uma intervenção eficaz antes do ataque de uma infecção oportunista ou o desenvolvimento da própria síndrome da imunodeficiência humana adquirida, bem como ajuda a prevenir que o indivíduo diagnosticado continue transmitindo o vírus. 
O maior desafio quanto a prevenção é a informação adequada da população, principalmente a população destacada no estudo. Vinda por meio de educação em saúde. Tal educação deve ser iniciada com profissionais de saúde bem preparados no intuito de aconselhar usuários quando estes procurarem pelo serviço. Além disso, promover busca ativa entre a população vulnerável, tanto para diagnosticar os indivíduos que desconhecem a infecção quanto para possibilitar uma prevenção eficiente entre estes. Promovendo orientações em escolas, clubes, entidades sociais e demais locais públicos.

Os aspectos sociais são de grande influência na epidemia do vírus HIV, a falta de recursos, de acesso à informação e à educação geram dificuldade no controle da epidemia. Por isso se faz tão necessária a adoção de medidas públicas de conscientização e a facilidade no acesso a insumos de prevenção e diagnóstico.

\section{Referências Bibliográficas Eletrônicas}

ANJOS, R. H. D, Silva JAS, Val LF, Rincon LA, Nichiata LYI. Diferenças entre adolescentes do sexo feminino e masculino na vulnerabilidade individual ao HIV. RevEscEnferm USP [internet]. 2012 [acesso em 2015 jul 11]; 46(4):829-837. Disponível em: http://www.scielo.br/pdf/reeusp/v46n4/07.p $\underline{\mathrm{df}}$
ARAÚJO, C. L. F, Costa LPM, Schilkowsky LB, Silva SMB. Os centros de testagem e aconselhamento (CTA) no município do Rio de Janeiro e o acesso ao diagnóstico do HIV entre população negra: uma análise qualitativa. Saúde Soc. São Paulo[internet]. 2010 [acesso em 2015 jul 11]; 19(2):85-95. Disponível em: http://www.revistas.usp.br/sausoc/article/vie $\mathrm{w} / 29693 / 31567$

BRASIL. Agência Nacional de Vigilância Sanitária. Resolução - RDC no 34, de 11 de junho de 2014. Dispõe sobre as boas práticas do ciclo do sangue. Brasília; 2014.

Coelho RFS, Souto TG, Soares LR, Lacerda LCM, Matão MEL. Conhecimentos e crenças sobre doenças sexualmente transmissíveis e HIV/AIDS entre adolescentes e jovens de escolas públicas estaduais da região oeste de Goiânia. Revista de patologia tropical [internet]. 2011 [acesso em 2015 abr 26]; 40(1):56-66. Disponível:

http://revistas.jatai.ufg.br/index.php/iptsp/ article/view/13914/8859

FERREIRA, B. E, Oliveira IM, Paniago AMM. Qualidade de vida de portadores de HIV/AIDS e sua relação com $\mathrm{CD} 4+$, carga viral e tempo de diagnóstico. RevBrasEpidemiol [internet]. 2012 [acesso em 2015 abr 26]; 15(1):75-84. Disponível em: http://www.scielo.br/pdf/rbepid/v15n1/ 07.pdf

GUIMARÃES, M. D. C, Ceccato MGB, Gomes RRFM, Rocha GM, Camelo LV, Carmo RA et 
al. Vulnerabilidade e fatores associados a HIV e sífilis em homens que fazem sexo com homens, Belo Horizonte, MG. Ver Med Minas Gerais [internet]. 2013 [acesso em 2015 mar 22]; 23(4):412-426.

Disponível:

file:///C:/Users/Amanda\%20Ruas/Download s/v23n4a02. pdf

JUNIOR, J. S. M; GOMES R, Nascimento EF. Masculinidade hegemônica, vulnerabilidade e prevenção ao HIV/AIDS. Ciência e Saúde Coletiva [internet]. 2012 [acesso em 2015 jul 11]; 17(2):511-520. Disponível em: http://www.scielosp.org/pdf/csc/v17n2/a24v 17n2.pdf

MARQUES, S. C; OLIVEIRA D. C, GOMES, A. M. T, Penna LHG, Spíndola T. A oferta do teste anti-HIV às usuárias das unidades da rede básica de saúde: diferentes abordagens dos profissionais. J. res.: fundam. care online [internet]. 2015 [acesso em 2015 mar 22]; 7(1):1891-1904.

Disponível: http://www.seer.unirio.br/index.php/cuidadof undamental/article/view/4120/ pdf1424http://www.seer.unirio.br/index.php/ cuidadofundamental/article/view/4120/pdf 1 $\underline{425}$

MARTINS T. A. KERR, L. R. F. S, KENDALL C, MOTA R. M. S. Cenário Epidemiológico da Infecção pelo HIV e AIDS no Mundo. RevFisioter S Fun [internet].2014 [acesso em 2015mar 22]; $\quad 3(1): 4-7$.

Disponível:http://www.fisioterapiaesaudefunci onal.ufc.br/index.php/

fisioterapia/article/view/ 425

MEIRELLES B. H. S, SILVA, D. M. G. V; VIEIRA, F. M. A, SOUZA, S. S, COELHO, I. Z, BATISTA, R. Percepções da qualidade de vida de pessoas com HIV/AIDS. Rev. Rene. Fortaleza [internet]. 2010 [aceso 2015 mar 22]; 11(3):68-76. Disponível em: http://www.revistarene.ufc.br/revista/index. $\mathrm{php} /$ revista/ article/view/397

NETO, C. A; JÚNIOR, A. M, SALLES, N. A; CHAMONE, D. A. F; SABINO, E. C. O papel do médico na redução do risco residual da transmissão do vírus da imunodeficiência humana (HIV) por transfusão de sangue e hemocomponentes. Diagn Tratamento [internet]. 2009 [acesso em 2015 jun 07]; 14(2):57-61. Disponível em: http://files.bvs.br/upload/S/14139979/2009/v14n2/a0002.pdf

NETO JFR, Lima LS, Rocha LF, Lima JS, Santana KR, Silveira MF. Perfil de adultos infectados pelo vírus da imunodeficiência humana (HIV) em ambulatório de referência em doenças sexualmente transmissíveis no norte de Minas Gerais. RevMed Minas Gerais [internet]. 2010 [acesso em 2015 jul 11]; 20(1):22-29. Disponível em: http://rmmg.org/artigo/detalhes/379 PASCHOAL, E. P, SANTO, C. C. E, GOMES; A. M. T, SANTOS, E. I; Oliveira DC, PONTES; 
A. P. M. Adesão à terapia antirretroviral e suas representações para pessoas vivendo com HIV/AIDS. Esc Anna Nery [internet]. 2014 [acesso em 2015 mar 22]; 18(1):32-40. Disponível em: http://www.scielo.br/scielo.php?script=sci art $\underline{\text { text\&pid }=\text { S1414-81452014000 } 100032}$

PEREIRA, B. S; COSTA, M. C. O; AMARAL M. T. R; COSTA, H. S, SILVA, C. A. L, SAMPAIO, V. S. Fatores associados à infecção pelo HIV/AIDS entre adolescentes e adultos jovens matriculados em Centro de Testagem e Aconselhamento no Estado da Bahia, Brasil. Ciência \& Saúde Coletiva [internet]. 2014 [acesso em 2015 mar 22]; 19(3):747-758. Disponível em: http://www.scielosp.

org/pdf/csc/v19n3/1413-8123-csc-19-03-

00747.pdf

PINHEIRO, T. F, Calazanas GJ, Ayres JRCM. Uso de camisinha no Brasil: Um olhar sobre a produção acadêmica acerca da prevenção de HIV/Aids (2007-2011). Temas em psicologia [Internet]. 2013 [acesso em 2015 mar 22]; 21(3):815-836. Disponível em: http://pepsic.bvsalud. org/scielo.php?pid=S1413$\underline{389 X 2013000300009 \& \text { script }=\text { sci arttext }}$

REIS, R. K, Santos CB, Dantas RAS, Gir E. Qualidade de vida, aspectos sociodemográficos e de sexualidade de pessoas vivendo com HIV/AIDS. Texto Contexto Enferm [internet]. 2011 [acesso em 2015 mar 22]; 20 (3): 565 - 575.
Disponível em: http://www.scielo.br/pdf/tce/ v20n3/19.pdf

SILVA, E. S, Paiva A. M. B, COSTA, A. S, FERREIRA V, OLIVEIRA M. G, SOUZA M. S. P. Perfil socioeconômico dos usuários da rede nacional de pessoas vivendo e convivendo com HIV/AIDS - Núcleo de Campina Grande-PB. In: XV Encontro Latino Americano de Iniciação Científica e XI Encontro Latino Americano de Pós-Graduação - Universidade do Vale do Paraíba; 2011 out 21 e 22; São José dos Campos, Brasil. 2010.

SILVA M. J. G, LIMA F. S. S, HAMANN, E. M. Uso dos serviços públicos de saúde para DST/HIV/AIDS por comunidades remanescentes de quilombos no Brasil. Saúde Soc. São Paulo [internet]. 2010 [acesso em 2015 jul 11]; 19 (2): 109 - 120. Disponível em: http://www.revistas.usp.br/sausoc/ article/view/29695/31569

TAQUETTE, S. R. Meirelles ZV. Convenções de gênero e sexualidade na vulnerabilidade às DSTs/AIDS de adolescentes femininas. Adolescentes. Saúde [internet]. 2012 [acesso em 2015 jul 11]; 9 (3): 56 - 64. Em: file:///C:/Users/Amanda\%20Ruas/Download s/v9n3a08\%20(1).pdf

TIBÚRCIO, A. S. Avaliação imunovirológica inicial de pacientes com HIV/AIDS em um serviço de assistência especializada. J bras Doenças Sex Transm [internet]. 2010 [acesso em 2015 abr 26]; 22(1):7-9. Disponível em: 
http://www.dst.uff.br/revista22-1-2010/1-

\%20Avaliacao $\% 20$

imunovirologica $\% 20 \mathrm{de} \% 20$ Pacientes $\% 20 \mathrm{com}$

\%20HIV-Aids.pdf

WERSON, E. S. S; MOTTA, L. R; BAZZO, M.

L; FRANCHINI M; JUNIOR, O. C. F;

MANUAL, técnico para o diagnóstico da infecção pelo HIV. Brasília: Ministério da Saúde; 2013. 